\title{
St Gallen Globe Online
}

\author{
Jost Schmid $^{\mathrm{a}, *}$, Joshua Binswanger ${ }^{\mathrm{b}}$ \\ ${ }^{a}$ Zentralbibliothek Zurich (Map Department) - jost.schmid@zb.uzh.ch, \\ ${ }^{b}$ University of Zurich (Digital Library Space)/Zurich University of the Arts (ZHdK) - joshua.binswanger@zhdk.ch \\ * Corresponding author
}

Keywords: St Gallen Globe, Knowledge Visualization, Citizen Science, 3D modeling

\begin{abstract}
:
During the Toggenburg war 1712, the St. Gallen Globe was taken to Zurich as booty. Despite a peace treaty to the contrary, the globe was never returned. It remained a disputed cultural asset between the cantons of Zurich and St Gallen. After mediation by the Federal Council in 2006, it was finally agreed that the globe would remain in the Swiss National Museum in Zurich, but that the canton of Zurich would have to produce a replica true to the original for St. Gallen. A memorandum of understanding was signed by the National Museum, the Abbey Library of St Gallen and the Zentralbibliothek when the replica was handed over. The aim was to create a web-based version of the globe. Until now, however, this intention has not yet been implemented.

During the replication work (2007-2009), the surface of the sphere was digitally measured and photographed. In the following years, other image data have been produced and numerous analyses were carried out. In the process, some groundbreaking discoveries were made. For example, radiography and infrared reflectography examinations revealed underdrawings with portraits of overpainted contemporaries. These portraits gave clues to the context of origin and dating of the globe, which were not known before.

In 2019 the ETH Institute of Geodesy and Photogrammetry found a way to project the image data of the surface of the globe onto a virtual sphere. The Abbey Library then had its replica digitised and virtualised by the same institute in the same year. At this point, the above mentioned Swiss cultural institutions were sure that the technology was ripe to implement the 12-year-old project in a meaningful and innovative way, and they met on 31 August 2021 in order to finally create a browser-based replica of the globe. In a first step, a basic model will be financed by the partners mentioned above and built by the Zurich University of the Arts (ZHdK) until fall 2022. In a second step, the basic model will be developed in a research project over three years' time in order to enable interactive Citizen Science- and Knowledge Visualization-projects to initiate a transfer from science to science and from science to public. One of our approaches is based on narratives that are told by the globe. Other approaches will include Gamification and Scientainment aspects as well. Until December 2021, the University of Zurich (Digital Library Space) together with the "ZB-Lab" (Zentralbibliothek Zurich) are creating a prototype that will illustrate some of these functions. This prototype will be presented in this poster.
\end{abstract}

\section{Acknowledgements}

Thanks to the Abbey Library of St Gallen, the Swiss National Museum, the Zentralbibliothek Zurich, the Zurich University of the Arts (ZHdK), the ETH Institute of Geodesy and Photogrammetry and the University of Zurich (Digital Library Space).

\section{References}

Schmid, J., 2019. Der St. Galler Globus - Ein kosmographisches Modell des Tilemann Stella, (Monasterium Sancti Galli 9).

Schnürer, R., Sieber, R., Schmid, J., Öztireli, A. C., and Hurni, L., 2020. Detection of Pictorial Map Objects with Convolutional Neural Networks, The Cartographic Journal, DOI: 10.1080/00087041.2020.1738112 


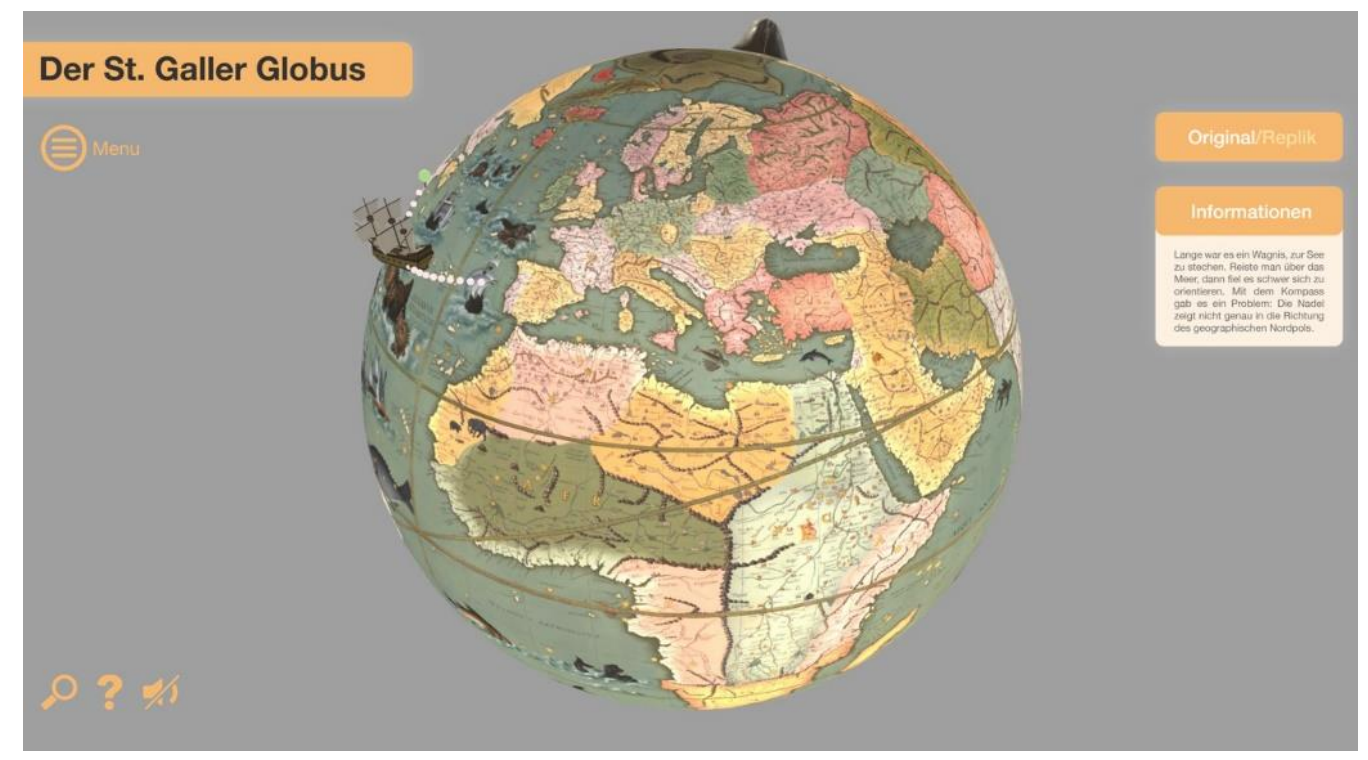

Figure 1. Storytelling and Knowledge Visualization on the St Gallen Globe Online: The difficulty of navigation with the magnetic compass illustrated with a moving ship and the magnetic mountain (polus magnetis) () Joshua Binswanger. 